\title{
Muir-Torre syndrome
}

INSERM

\section{Source}

INSERM. (1999). Orphanet: an online rare disease and orphan drug data base. Muir-Torre syndrome. ORPHA:587

Muir-Torre syndrome (MTS) is a form of hereditary nonpolyposis colon cancer (HNPCC) characterized by cutaneous sebaceous tumors, keratoacanthomas and at least one visceral malignancy, most frequently gastrointestinal carcinoma. 